\title{
Scavenger receptors: a key player in cardiovascular diseases
}

\author{
Mohammad Z. Ashraf* and Anita Sahu \\ Genomics Group, Defence Institute of Physiology and \\ Allied Sciences, Lucknow Road, Timarpur, Delhi 110054, \\ India \\ * Corresponding author \\ e-mail: mohammadzashraf@gmail.com
}

\begin{abstract}
The scavenger receptor (SR) super family consists of integral membrane glycoproteins that are involved in recognition of polyanionic structures of either endogenous (e.g., oxidized low-density lipoprotein) or exogenous (e.g., bacterial lipopolysaccharides) origin. SRs are structurally diverse and can be classified into seven different classes (A-G) based on the multidomain structure of the individual members. SRs are present on various types of tissues, such as vascular, adipose, and steroidogenic tissues. In addition to modified lipoprotein uptake, these proteins are also known to regulate apoptotic cell clearance, initiate signal transduction, and serve as pattern recognition receptors for pathogens. Different SRs are involved in many physiological and pathological processes; more importantly, the function of SRs is highly implicated in the initiation and progression of atherosclerotic plaque. Targeting the SR gene products that mediate the response to and uptake of modified lipids holds great promise in the prevention of cardiovascular diseases. Inhibition of SR expression using a combined gene therapy and RNA interference strategy also appears to be an option for long-term therapy. The present review focuses on the involvement of SRs in atherosclerosis, thrombosis, and other cardiovascular diseases. Moreover, the role of SRs is not restricted to vascular lesions; it is also implicated in a number of different cellular functions.
\end{abstract}

Keywords: atherosclerosis; lipoproteins; oxidized phospholipids; scavenger receptors; thrombosis.

\section{Introduction}

Scavenger receptors (SRs) comprise a structurally diverse group of membrane-bound proteins that are involved in cholesterol and lipoprotein metabolism. SRs were initially identified as macrophage receptors based on their ability to recognize modified lipoproteins (1). Several classes of SRs (from A to $G$ ) have been identified so far depending on the presence of shared structural domains; however, there is a great structural diversity among different classes (Figure 1) (2). SRs are present on different tissues including macrophages, monocytes, platelets, endothelial cells, smooth muscle, and epithelial cells. In addition to vascular tissues, they also have been detected in adipose and steroidogenic tissues (2). SRs bind to a wide range of ligands including modified high density lipoprotein (HDL), low density lipoprotein (LDL) particles, and other polyanionic ligands such as acetylated lowdensity lipoprotein (AcLDL), oxidized low-density lipoprotein (OxLDL), Gram-positive and Gram-negative bacteria, apoptotic cells, $\beta$-amyloid fibrils, and advanced glycation end products (AGE) (Table 1) (3). Because of its ability to bind diverse ligands and perform multiple functions, SRs have the potential to be involved in many physiological and pathological processes such as homeostasis, apoptotic cell clearance, and innate immunity. More importantly, these receptors have been highly implicated in atherosclerotic plaque initiation and progression as well (4).

Targeting the SR gene products that mediate the response to and uptake of modified lipids holds great promise in the prevention of cardiovascular diseases. The present review emphasizes the role of these receptors in atherosclerosis, thrombosis, and other cardiovascular complications.

\section{Class-A SRs}

Class-A SRs are trimeric transmembrane glycoproteins that are expressed primarily by macrophages and bind a variety of ligands, including modified lipoproteins, bacterial products, and extracellular matrix proteins (Table 1). Class-A SRs mediate ligand internalization as well as cell adhesion $(5,6)$. Class-A SRs comprise at least four types of receptors: scavenger receptor A (SR-A), macrophage receptor with collagenous structure (MARCO), scavenger receptor with C-type lectin (SRCL), and scavenger receptor A-5 (SCARA5) (7-9).

SR-A are largely found on macrophages, but are also present on platelets, endothelial cells, and vascular smooth muscle cells. These receptors are postulated to be proatherogenic due to their ability to mediate uptake of OxLDL in macrophages and platelets $(10,11)$. Initial studies of SR-Anull $\left(\mathrm{Msr}^{--}\right)$mice were performed in atherosclerosis-susceptible ApoE-deficient $\left(\mathrm{ApoE}^{-/-}\right)$mice on a hybrid background (ICR/129) fed a chow diet; animals showed a 58\% decrease in aortic sinus atherosclerosis lesion area compared with ApoE ${ }^{-/-}$littermates (11). The combined action of cluster differentiation 36 (CD36) (another class-B SR) and SR-A has been well demonstrated via a new mechanism in which 


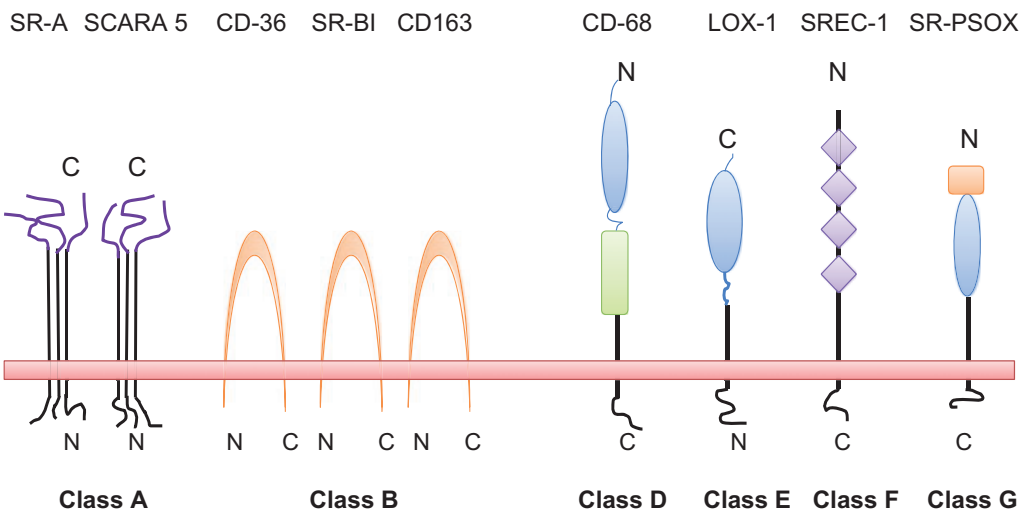

Figure 1 A schematic showing the major SRs.

platelet activation is stimulated by the combined action of CD36 and SR-A. The results showed that combined blockage of CD36 and SR-A completely shut down the p38 mitogen activated protein kinase (MAPK) phosphorylation induced by OxLDL, but had no effect on native LDL signaling activities. Activation of p38 MAPK by OxLDL enhanced the adhesion of platelets and blocking these two receptors significantly reduced the adhesion of platelets to immobilized fibrinogen. Further study using murine platelets that were deficient in either CD36 or SR-A shows that these two SRs are required for OxLDL signaling in platelets $(12,13)$. Recently, Mäkinen et al. have studied the role of SR-A and CD36 in foam cell formation and atherogenesis by RNA interference (14). They employed RNA interference (RNAi)-mediated silencing to downregulate the expression of these receptors. They found that decreased SR-A but not CD36 expression led to reduced foam cell formation caused by AcLDL in mouse macrophage, whereas the uptake of OxLDL was not altered. More importantly, silencing of SR-A upregulates CD36 and vice versa. In another set of experiment, when low density lipoprotein receptor $(\mathrm{LDLR})^{-/ /} / \mathrm{ApoB}^{100 / 100}$ mice were kept on a Western diet, silencing of either SR-A or CD36 in bone marrow cells led to a marked decrease in lesion area, whereas simultaneous silencing of both receptors was not effective (14).

MARCO is expressed largely on macrophages and to a lower extent on dendritic cells (15). MARCO is implicated in host defense and pathogen clearance as binding to dead or apoptotic cells, bacteria, and lipopolysaccharides (LPS) elevates MARCO levels (16). When challenged with Streptococcus pneumoniae, wild-type (WT) mice could clear the infection, whereas this ability was impaired in $\mathrm{MARCO}^{--}$mice, demonstrating the role of MARCO in the innate immune response against pathogens (17). MARCO expression in human alveolar macrophages also plays a crucial role in the innate immunity against bacteria (18). However, the roles of MARCO in binding modified LDL and in atherogenesis have been less well studied.

In contrast to the other class-A gene products, SRCL is detected on endothelial cells but not macrophages and are thought to be involved in innate immune response against fungal infections $(19,20)$. SCARA5 is also detected on epithelial cells but not macrophages and may play a unique role in the innate immune system and atherosclerosis (7). In a study, it was found that catechin reduces atherosclerotic lesion

Table 1 Major SR and their ligands and expression profiles.

\begin{tabular}{|c|c|c|c|}
\hline SR & Class & Ligands & Expression profile \\
\hline SR-A & SR-A & $\begin{array}{l}\text { AcLDL, OxLDL, } \beta \text {-amyloid, molecular chaperones, } \\
\text { apoptotic cells, and activated B-cell, bacteria }\end{array}$ & $\begin{array}{l}\text { Macrophages, mast, dendritic, endothelial, } \\
\text { and smooth muscle cells }\end{array}$ \\
\hline MARCO & SR-A & $\begin{array}{l}\text { AcLDL, OxLDL, apoptotic cells, B cells, and } \\
\text { bacteria }\end{array}$ & Macrophages and dendritic cells \\
\hline CD36 & SR-B & $\begin{array}{l}\text { OxLDL, HDL, LDL, VLDL, } \beta \text {-amyloid, and } \\
\text { apoptotic cells }\end{array}$ & $\begin{array}{l}\text { Macrophages, platelets, adipocytes, epithelial, } \\
\text { and endothelial cells }\end{array}$ \\
\hline SR-B & SR-B & HDL, LDL, OxLDL, and apoptotic cells & $\begin{array}{l}\text { Monocytes/macrophages, hepatocytes, and } \\
\text { adipocytes }\end{array}$ \\
\hline Macrosialin/CD68 & SR-D & OxLDL & Macrophages, and dendritic cells \\
\hline LOX-1 & SR-E & $\begin{array}{l}\text { OxLDL, apoptotic cells, activated platelets, and } \\
\text { bacteria }\end{array}$ & $\begin{array}{l}\text { Endothelial and smooth muscle cells, mac- } \\
\text { rophages, and platelets }\end{array}$ \\
\hline SREC-I/II & SR-F & $\begin{array}{l}\text { AcLDL, OxLDL, molecular, chaperones, and } \\
\text { apoptotic cells }\end{array}$ & Endothelial cells and macrophages \\
\hline SR-PSOX & SR-G & OxLDL and bacteria & $\begin{array}{l}\text { Macrophages, smooth muscle, dendritic, } \\
\text { endothelial cells, and B and T cells }\end{array}$ \\
\hline
\end{tabular}


development in ApoE-deficient mice. The expression of 450 genes was significantly modified by catechin supplementation. Genes involved in energy metabolism, lipid metabolism, and lipid trafficking such as FABP4, LPL, and SCARA5 were downregulated and may contribute to the atheroprotective effect of catechin (21).

\section{Class-B SRs}

Unlike the SR-A family, class-B SRs have multiple transmembrane domain receptors (Table 1). Class B contains three members: CD36, scavenger receptor class B member 1 (SR-BI), lysosomal integral membrane protein II, and cluster differentiation 163 (CD163) (2). Despite the high degree of homology between CD36 and SR-BI, these two receptors appear to play distinct roles in lipid metabolism and atherosclerosis.

\section{CD36}

CD36 is an $88 \mathrm{kDa}$ membrane glycoprotein that was first identified on monocytes by monoclonal antibody OKM5 (22). CD36 has an unusual structural organization, with two transmembrane domains, two very short intracytoplasmic domains, and a large heavily glycosylated extracellular domain. Both of the intracellular domains contain pairs of cysteines that are fatty acid acylated, thus presumably closely opposed to the inner leaflet of the cell membrane (23).

CD36 is present on many mammalian cell types, including platelets, erythroid precursors, and microvascular endothelium; most 'professional' phagocytes (macrophages, dendritic cells, microglia, and retinal pigment epithelium); hepatocytes; adipocytes; cardiac and skeletal myocytes, epithelia of the gut, breasts, and kidneys (24). The diverse group of ligands that bind to CD36 consists of oxidized phospholipids, thrombospondin-1, collagen, various microbial pathogens, apoptotic cells, fatty acids, and microbial diacylglycerides (24, 25). CD36 affects very different cellular processes depending upon the nature of the ligand and the type and location of the cell that expresses it (26).

The function of CD36 is complex and has been associated with diverse physiological processes (for instance, uptake of modified lipid and apoptotic cells, long-chain fatty acid transport, adhesion, and angiogenesis), and its expression or deficiency has been linked with several pathological conditions, such as atherosclerosis, diabetes, inflammation, and cardiomyopathy (24). Studies of mice with targeted deletion of the CD36 gene have shown that loss of CD36 confers protection from diet-induced atherosclerosis; this limits inflammation and tissue infarction associated with acute cerebrovascular occlusion, but may increase susceptibility to certain infections $(27,28)$.

Further studies have confirmed that the proatherogenic role of CD36 was highly likely to be mediated by the CD36 on macrophages, as transplantation of bone marrow from CD36null mice into ApoE-null mice had the same effect on atherosclerosis as seen in the ApoE/CD36-double-null mice (27).
On macrophages, CD36 plays an important role in foam cell formation. Incubation of CD36-deficient monocytes/ macrophages with OxLDL resulted in a 40\%-60\% reduction in OxLDL binding and uptake compared to WT CD36expressing cells. Macrophages isolated from CD36-null mice have a profound defect in OxLDL uptake and foam cell formation. Crossing the CD36-deficient mice with a proatherogenic ApoE-null animal resulted in a significant protection from lesion development. More importantly, animals fed with a Western diet showed a $70 \%$ reduction in aortic lesion size and distribution $(29,30)$.

Although much is known about the mechanism of OxLDL interactions with macrophages, only recent studies have demonstrated that CD36 also mediates platelet responses to OxLDL and contributes to the procoagulant state associated with hyperlipidemia and oxidative stress (31). Podrez et al. demonstrated that CD36 might serve as a kind of primer or sensitizer for platelet activation leading to platelet hyperreactivity in response to various forms of OxLDL or specific oxidized choline glycerophospholipids $\left(\mathrm{oxPC}_{\mathrm{CD} 36}\right)$ that are formed during LDL oxidation. In hyperlipidemic CD36- ${ }^{-1}$ $\mathrm{ApoE}^{-/-}$mice, the absence of CD36 significantly protected these mice from the hyperlipidemia-related prothrombotic phenotype when compared to hyperlipidemic $\mathrm{ApoE}^{-/-}$without CD36 deficiency (32). In vitro, various forms of OxLDL and oxPC ${ }_{\mathrm{CD} 36}$ bind to human and mouse platelets in a CD36dependent manner. Binding of these ligands to CD36 resulted in platelet activation, characterized by the increased integrin $\alpha \mathrm{IIb} \beta 3$ and P-selectin surface expressions (33).

A significant increase in the extent and rate of aggregation of platelets from hyperlipidemic $\mathrm{ApoE}^{-/-}$mice was compared to WT mice. This response was primarily blunted in platelets from ApoE ${ }^{-/-}$and CD36 $6^{-/}$mice. No significant differences were observed between platelets from $\mathrm{WT}$ and $\mathrm{CD}_{3} 6^{-1-}$ mice on normal chow diet, thereby indicating that CD36 plays an important modulatory role in platelet function only in the setting of hyperlipidemia. Similar results were obtained when platelets from hyperlipidemic $\mathrm{LDLR}^{-/}$mice were compared to platelets from $\mathrm{LDLR}^{-/}$and $\mathrm{CD} 36^{-/-}$mice. Role of CD36 in thrombosis is restricted to the dyslipidemic milieu, where there is enhanced oxidative stress that can generate specific ligands for CD36 (33).

Dawson et al. identified CD36 on endothelial surface that mediates its antiangiogenic activity. CD36-mediated antiangiogenesis is triggered by its ability to activate a specific signaling cascade that results in diversion of a proangiogenic response to an apoptotic response (34). Recently, Li et al. have shown that CD36 was abundantly expressed by murine arterial smooth muscle cells and the absence of CD36 attenuated reactive oxygen species (ROS) production in response to ferric chloride-induced vascular injury in a mouse carotid artery thrombosis model. These data suggest that CD36-mediated downregulation of antioxidant systems in vascular smooth muscle cells may contribute to its prothrombotic, proinflammatory, and proatherogenic effects (35).

When CD36 binds to its ligands OxLDL and microparticles, it transmits a signal to the cell. In macrophages, this signal leads to OxLDL internalization and foam cell formation, 
whereas in platelets, it contributes to platelet activation and aggregation. It has been shown that these signals are relayed by a series of molecular interactions that involve specific tyrosine kinases from the Src family, serine/threonine kinases family, and MAPK family. The signal to the platelet is mediated by a MAPK called c-Jun N-terminal kinase (JNK). CD36- mice had $16 \%$ less phosphor JNK than those from WT mice. Inhibition of platelet JNK significantly prolonged the time to thrombosis in mice transfused with WT platelets, but had no effect in mice transfused with $\mathrm{CD} 36^{-/}$platelets. These data strongly suggested that CD36-mediated JNK signaling promotes platelet activation and thrombus formation in vivo (36), thereby indicating that CD36 has both a proatherogenic and a prothrombotic role in the vascular system.

In addition to atherosclerosis, CD36 has also been implicated in promoting chronic inflammation in Alzheimer's disease. Binding of $\beta$-amyloid fibrils with CD36 initiates inflammatory signaling pathways leading to microglial activation, ROS production, and secretion of cytokines and chemokines. Interestingly, amyloid ligands, including $\beta$-amyloid and fibrillar apolipoproteins (C-II and A-I), have also been detected in human atheroma, and these ligands can initiate proinflammatory CD36 signaling that may drive inflammation in the artery wall $(37,38)$.

\section{SR-BI}

SR-BI, an $82 \mathrm{kDa}$ membrane glycoprotein, contains a large extracellular domain and two transmembrane domains with a short cytoplasmic N- and C-terminal tail. SR-BI is expressed on the surface of macrophages, platelets, and steroidogenic tissues mainly in the adrenals, ovary, hepatocytes, and to some extent on endothelial cells (39). Like CD36, it also binds to a variety of ligands including native lipoproteins, oxidized lipoproteins, AGE, and anionic phospholipids, and plays a pivotal role in cholesterol metabolism (40).

The major physiological function of SR-BI is to mediate the selective transport of cellular uptake of lipids, especially cholesteryl esters from HDL and the bidirectional flux of unesterified cholesterol between cells and lipoprotein (40). Hepatic SR-BI regulates plasma lipoprotein metabolism, biliary cholesterol secretion, and the structure and composition of plasma HDL particles. Overexpression of SR-BI protein in mouse liver has been found to be associated with reduced levels of plasma HDL cholesterol, thus implicating a possible role for SR-BI in the transport of cholesterol from peripheral tissues to the liver (41). Besides, there are a number of evidences where SR-BI and CD36 have been described.

In an earlier study, it has been demonstrated that oxPC ${ }_{\mathrm{CD} 36}$ bind specifically to SR-BI and that binding of oxPC ${ }_{\mathrm{CD} 36}$ prevents HDL association because of the close proximity of the binding sites for these two ligands on SR-BI. Moreover, ${ }^{\text {oxPC }} \mathrm{CD}_{36}$ has been recognized as a potent inhibitor of SR-BImediated uptake of cholesteryl esters in hepatocytes. Results obtained revealed that specific oxidized phospholipids that accumulated in vivo in oxidative stress may inhibit reverse cholesterol transport and contribute to the development of hypercholesterolemia and atherosclerosis (42).
Furthermore, the expression of SR-BI in lipid-laden macrophages in human and murine atherosclerotic lesions (43) implicates that SR-BI might play an important role locally in the arterial wall. On the one hand, SR-BI expression by macrophage may protect against atherosclerosis by stimulating cholesterol efflux and preventing foam cell formation. On the other hand, its function in the uptake of both modified and native lipoproteins might enhance foam cell formation, thus rendering macrophage SR-BI a proatherogenic factor (44). Zhang et al. demonstrated that inactivation of macrophage SR-BI promotes the development of atherosclerosis in ApoEdeficient mice in the absence of changes in plasma lipids, HDL subpopulations, and cholesterol efflux (45).

Studies have also demonstrated that SR-BI in bone marrowderived cells facilitates the development of small fatty streak lesions in both $\mathrm{LDLR}^{-/}$mice on Western type diet for only 4 weeks and in WT mice fed with a high-cholesterol diet. These data supported a unique dual role for SR-BI on bone marrowderived cells including macrophages in atherosclerotic lesion development (46). Furthermore, binding of HDL to SR-BI on endothelial cells induces the production of nitric oxide (NO) by upregulating endothelial NO synthase (eNOS) expression through a kinase cascade and has a protective effect on hypercholesterolemia-induced vascular disease (47).

Imachi et al. reported reduced levels of SR-BI on platelets from atherosclerotic disease patients that were inversely correlated with the intracellular cholesterol content of platelets and their ability to aggregate (48). Disruption of SR-BI in mice resulted in a three-fold increase in free cholesterol levels in the circulation, resulting in an unusually high plasma unesterified to total cholesterol ratio (UC/TC) (49). Dole et al. described that the high UC/TC ratio observed in SR-BIdeficient mice is associated with thrombocytopenia due to high platelet clearance rates, increased intracellular cholesterol content, and abnormal platelet morphologies (49). Recently, Korporaal et al. found that disruption of SR-BI in mice resulted in active circulating platelets, increased adherence to immobilized fibrinogen, and increased susceptibility to arterial thrombosis in vivo. Hence, SR-BI is essential not only for HDL cholesterol homeostasis and atherosclerosis susceptibility, but also for maintaining normal platelet function and prevention of thrombosis (50).

Furthermore, Ma et al. investigated the effect of SR-BI deficiency on platelet aggregation and thrombosis. They found that SR-BI deficiency alone, under normolipidemic conditions, does not lead to a major defect in platelet aggregation, while hyperlipidemic milieu associated with non-bone marrow-derived SR-BI deficiency is the major cause of the thrombocytopenia and abnormal morphology (51).

An earlier study by the same group has shown SR-BI as the platelet SR that mediates the antiplatelet activity of OxHDL. Interestingly, the antiplatelet effect of OxHDL/SR-BI communication was independent of the eNOS/protein kinase B pathway, known to play a role in HDL/SR-BI-induced eNOS activation in endothelial cells. These results were suggestive of a dual role played by SR-BI in platelet function and thrombosis. Studies using chimeric mice revealed that nonbone marrow-derived SR-BI deficiency leads to platelet 
hyperreactivity and thrombocytopenia, and platelet-specific $\mathrm{SR}-\mathrm{BI}$ is required for normal platelet responses (52).

Although CD36 and SR-BI have been shown to bind OxLDL with similar high affinity, the metabolism of OxLDL by these two class-B SRs has not been compared directly. However, in a study, it was found that CD36 and SR-BI differ in their ability to internalize and degrade OxLDL. Both class-B SRs might play an opposite role not only in the context of atherosclerosis, but also thrombosis; while CD36 promotes a prothrombotic phenotype, SR-BI might counteract thrombus formation by suppressing platelet activation (53).

\section{CD163}

CD163 is found to be expressed on monocytes and macrophages, in both membrane-bound and soluble forms. It plays an important role in the regulation of anti-inflammatory responses, pathogen recognition, and atheroprotection probably through elevation in expression of heme oxygenase and in removing free hemoglobin (54). Patients with hematological, inflammatory, and lysosomal storage diseases also have a high level of soluble CD163, and it may thus serve as a biomarker for such conditions (55).

\section{Class-D SRs}

Class D is comprised of CD68 (Macrosialin) which are heavily glycosylated type I transmembrane proteins and expressed in macrophages (56). Macrosialin levels are also observed to be increased by a proatherogenic diet. It has been identified as a receptor for OxLDL (57). Macrosialin receptor is expressed in macrophage foam cells in atherosclerotic plaques of $\mathrm{ApoE}^{-/-}$ mice, but its role in atherogenesis is unknown (58).

\section{Class-E SRs}

Class E comprises of just one member: the lectin-like OxLDL receptor 1 (LOX-1) (Table 1). It is a $50 \mathrm{kDa}$ type II membrane glycoprotein which contains a short N-terminal cytoplasmic domain, a single transmembrane domain, and an OxLDLbinding C-terminal extracellular C-type lectin-like domain (59). LOX-1 assembles on the cell surface in hexamer form or larger, comprising three homodimeric LOX-1 molecules bound to OxLDL. It is expressed on endothelial cells, macrophages, smooth muscle cells, and platelets. The ligands to which LOX-1 binds comprise of oxidized LDL, apoptotic cells, activated platelets, and bacteria, thereby signifying its implication in the pathogenesis of atherosclerotic lesions (60). The contributory role of LOX-1 in atherogenesis is supported by several lines of evidence: (i) OxLDL via activation of LOX-1 induces endothelial dysfunction/apoptosis, a major change in vascular biology seen at the beginning of atherogenesis (61); (ii) LOX-1 expression is dynamically upregulated in pathological conditions such as diabetes, hypertension, and dyslipidemia (62).

Macrophage LOX-1 depletion inhibits foam cell formation, suggesting a role in atherosclerotic plaque initiation and progression. Importantly, the incidence of atherosclerotic plaques is significantly lowered in LOX-1-deficient mice (63).

In endothelial cells, ligand binding to LOX-1 SR stimulates ROS production and both MAPK and nuclear factor- $\kappa \mathrm{B}$ activation, leading to increased expression of different adhesion gene products. Such elevated expression in endothelium can enable monocyte infiltration, ultimately leading to monocyte differentiation and foam cell formation (64).

LOX-1 was identified as a major binding protein for OxLDL on human platelets in addition to CD36. During platelet activation, fusion of $\alpha$ granule membranes with plasma membrane is followed by the translocation of LOX-1 toward the platelet surface. Earlier studies have demonstrated that blocking of LOX-1 retards the ADP-induced plateletactivation event, thus implicating its role in determining platelet physiology (65). Unlike CD36, LOX-1 is expressed only on activated platelets. This indicates that the two receptors function in different phases of platelet function. LOX-1 might be predominantly involved in thrombus formation, but does not appear to play a role in circulating resting platelets. When exposed on the activated platelet surface, it cross-links activated platelets and thus may stabilize thrombi or promote hemostasis (66).

\section{Class-F SRs}

Class F consists of the scavenger receptor expressed by endothelial cells I and II (SREC-I and SREC-II) which are type I transmembrane receptors containing $\mathrm{N}$-terminal epidermal growth factor-like domains, a transmembrane domain, and a long cytoplasmic tail postulated to induce signal transduction (4). These receptors are expressed on mammalian endothelial cells and macrophages. They bind modified lipoproteins such as AcLDL and OxLDL (67). Studies in SREC- $\mathrm{I}^{-/-}$macrophages demonstrated that this receptor accounts for only $6 \%$ of total AcLDL degradation, suggesting that it plays a minor role in foam cell formation (68).

\section{Class-G SRs}

The chemokine (C-X-C) ligand 16 is a class-G SR that binds to phosphatidylserine and oxidized lipoprotein (SR-PSOX). SR-PSOX is highly expressed on macrophages, smooth muscle cells, dendritic cells, kidney, and B and T cells with lower levels detected on the endothelium (69). This receptor is expressed in human and mouse atherosclerotic lesions, where it is present on endothelium, smooth muscle, and macrophages $(70,71)$. It is also involved in acute and adaptive experimental autoimmune encephalomyelitis, $\mathrm{CD}^{+} \mathrm{T}$ cell recruitment during inflammatory valvular heart disease, and bacterial phagocytosis (72).

\section{SRs as a potential therapeutic target}

SRs have a proatherogenic and a prothrombotic role in the vascular system (Figure 2). Ligands of SRs such as 


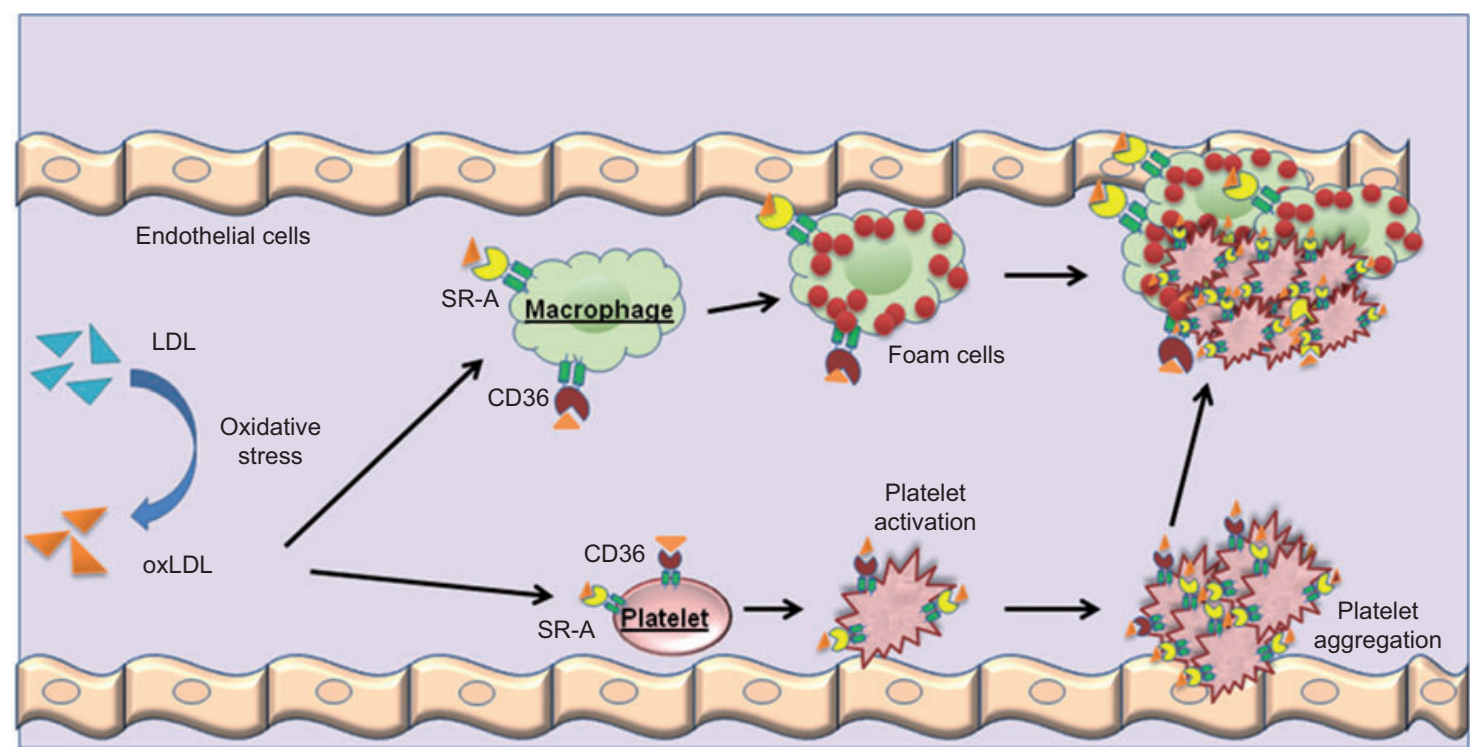

Figure 2 SRs and their role in atherothrombosis.

OxLDL, microparticles, and apoptotic cells are generated in vivo by oxidant stress, hyperlipidemia, inflammation, and cancer (29). The ability to understand and modulate these mechanisms may offer new treatment strategies for patients. Therefore, targeting some SRs and their signaling pathways could be a strategy in the treatment of cardiovascular diseases.

Siegel-Axel et al. demonstrated that platelet-induced foam cell generation from progenitor cells could be partially prevented by 3-hydroxy-3-methyl-glutaryl-coenzyme A reductase inhibitors and agonists of peroxisome proliferator activated receptor- $\alpha$ and $-\gamma$. Furthermore, they cloned and characterized an immune-adhesion molecule which resembles the SR CD68 and binds its ligand OxLDL with high affinity. CD68-Fc was found to bind to lipid-rich human atherosclerotic plaque specimens. CD68-Fc was able to inhibit plateletmediated macrophage foam cell formation and specific functions, such as matrix metalloproteinase- 9 activity in vitro. Thus, the inhibition of platelet-mediated foam cell formation may be a promising option to influence atherosclerotic plaque formation (73).

Recently, in a study, Hildebrand et al. investigated whether introduction of cholesteryl ester transfer protein (CETP) can normalize HDL-C transport to the liver and reduce atherosclerosis in SR-BI knockout (SR-BIKO) mice. They found that CETP restores HDL-C levels in SR-BIKO mice, but it does not change the susceptibility to atherosclerosis and other typical characteristics that are associated with SR-BI disruption. This may indicate that the pathophysiology of SR-BI deficiency is not a direct consequence of changes in the HDL pool (74).

Gene therapy can modulate SR function in atherosclerosis. Ectopic expression of membrane-bound SRs using viral vectors can modify lipid profiles and reduce the incidence of atherosclerosis. Alternatively, expression of soluble SRs can also block plaque initiation and progression. Inhibition of SR expression using a combined gene therapy and RNA interference strategy also holds promise for long-term therapy. RNAi-mediated treatment strategies of a single SR in macrophage might provide new ways to protect arteries against atherogenesis (75).

Although this review focuses on the role of SRs in arthrosclerosis, thrombosis, and other vascular diseases, nevertheless, the role of SRs is not restricted to vascular lesions; these receptors are also implicated in a number of different cellular functions.

Phagocytosis is mostly mediated by SRs. Phagocytic cells express a broad range of receptors that participate in recognition and engulfment of apoptotic and senescent cells, including CD36. CD36 recognizes pathogen-associated molecular patterns, including erythrocytes infected with Plasmodium falciparum (76). Animal studies with mice, genetically engineered to lack functional CD36, confirm that this SR participates in recognition and engulfment of apoptotic cells, senescence cells, or cell fragments (77). In addition to modified lipoprotein uptake, these proteins are now known to regulate apoptotic cell clearance, initiate signal transduction, and serve as a pattern recognition receptor for pathogens (78). Further studies in rodents and humans suggest that CD36 fatty acid interactions may contribute to the pathogenesis of metabolic disorders, such as insulin resistance, obesity, and non-alcoholic hepatic steatosis (79). A number of links have been established between SR-BI and many cardinal features of human cardiovascular disease, including hypercholesterolemia, atherosclerosis, occlusive fibrin-rich coronary artery lesions, ischemia, myocardial infarctions, and cardiac dysfunction (80).

Therefore, SR function is associated with both healthy and pathophysiological processes, such as homeostasis, apoptotic cell clearance, diabetic necropathy, age-induced cardiomyopathy, antigen cross-presentation in Alzheimer's disease, and different cardiovascular diseases. 


\section{Highlights}

SRs comprise a structurally diverse group of membranebound proteins.

SR function is associated with both physiological and pathophysiological processes.

These receptors are highly implicated in the initiation and progression of atherosclerosis, thrombosis, and other cardiovascular diseases.

Inhibition of SR expression using a combined gene therapy and RNA interference strategy holds a promise for long-term therapy.

\section{References}

1. Goldstein JL, Ho YK, Basu SK, Brown MS. Binding site on macrophages that mediates uptake and degradation of acetylated low density lipoprotein, producing massive cholesterol deposition. Proc Natl Acad Sci USA 1979; 76: 333-7.

2. Murphy JE, Tedbury PR, Homer-Vanniasinkam S, Walker JH, Ponnambalam S. Biochemistry and cell biology of mammalian scavenger receptors. Atherosclerosis 2005; 182: 1-15.

3. Plüddemann A, Neyen C, Gordon S. Macrophage scavenger receptors and host-derived ligands. Methods 2007; 43: 207-17.

4. Krieger M. The other side of scavenger receptors: pattern recognition for host defense. Curr Opin Lipidol 1997; 8: 275-80.

5. Platt N, Haworth R, Darley L, Gordon S. The many roles of the class A macrophage scavenger receptor. Int Rev Cytol 2002; 212: 1-40.

6. Gough PJ, Greaves DR, Gordon S. A naturally occurring isoform of the human macrophage scavenger receptor (SR-A) gene generated by alternative splicing blocks modified LDL uptake. J Lipid Res 1998; 39: 531-43.

7. Jiang Y, Oliver P, Davies KE, Platt N. Identification and characterization of murine SCARA5, a novel class A scavenger receptor that is expressed by populations of epithelial cells. J Biol Chem 2006; 281: 11834-45.

8. Nakamura K, Funakoshi H, Miyamoto K, Tokunaga F, Nakamura T. Molecular cloning and functional characterization of a human scavenger receptor with C-type lectin (SRCL), a novel member of a scavenger receptor family. Biochem Biophys Res Commun 2001; 280: 1028-35.

9. Kunjathoor VV, Febbraio M, Podrez EA, Moore KJ, Andersson L, Koehn S, Rhee JS, Silverstein R, Hoff HF, Freeman MW. Scavenger receptors class A-I/II and CD36 are the principal receptors responsible for the uptake of modified low density lipoprotein leading to lipid loading in macrophages. J Biol Chem 2002; 277: 49982-8.

10. Kamada N, Kodama T, Suzuki H. Macrophage scavenger receptor (SR-A I/II) deficiency reduced diet-induced atherosclerosis in C57BL/6J mice. J Atheroscler Thromb 2001; 8: 1-6.

11. Suzuki H, Kurihara Y, Takeya M, Kamada N, Kataoka M, Jishage K, Ueda O, Sakaguchi H, Higashi T, Suzuki T, Takashima Y, Kawabe Y, Cynshi O, Wada Y, Honda M, Kurihara H, Aburatani H, Doi T, Matsumoto A, Azuma S, Noda T, Toyoda Y, Itakura H, Yazaki Y, Horiuchi S, Takahashi K, Kruijt JK, Van Berkel TJC, Steinbrecher UP, Ishibashi S, Maeda N, Gordon S, Kodama T. A role for macrophage scavenger receptors in atherosclerosis and susceptibility to infection. Nature 1997; 386: 292-6.

12. Korporaal SJ, Van Eck M, Adelmeijer J, Ijsseldijk M, Out R, Listman T, Lenting PJ, Van Berkel TJ, Akkerman JW. Platelet activation by oxidized low density lipoprotein is mediated by
CD36 and scavenger receptor-A. Arterioscler Thromb Vasc Biol 2007; 27: 2476-83.

13. Korporaal SJ, Relou IA, van Eck M, Strasser V, Bezemer M, Gorter G, van Berkel TJ, Nimpf J, Akkerman JW, Lenting PJ. Binding of low density lipoprotein to platelet apolipoprotein $\mathrm{E}$ receptor 2 results in phosphorylation of p38 MAPK. J Biol Chem 2004; 279: 52526-34.

14. Mäkinen PI, Lappalainen JP, Heinonen SE, Leppänen $P$, Lähteenvuo MT, Aarnio JV, Heikkilä J, Turunen MP, YläHerttuala S. Silencing of either SR-A or CD36 reduces arthrosclerosis in hyperlipidaemic mice and reveals reciprocal upregulation of these receptors. Cardiovasc Res 2010; 88: 530-8.

15. Kraal G, van der Laan LJ, Elomaa O, Tryggvason K. The macrophage receptor MARCO. Microbes Infect 2000; 2: 313-6.

16. Grolleau A, Misek DE, Kuick R, Hanash S, Mulé JJ. Inducible expression of macrophage receptor MARCO by dendritic cells following phagocytic uptake of dead cells uncovered by oligonucleotide arrays. J Immunol 2003; 171: 2879-88.

17. Arredouani M, Yang Z, Ning YY, Qin G, Soininen R, Tryggvason $\mathrm{K}$, Kobzik L. The scavenger receptor MARCO is required for lung defense against pneumococcal pneumonia and inhaled particles. J Exp Med 2004; 200: 267-72.

18. Arredouani MS, Palecanda A, Koziel H, Huang YC, Imrich A, Sulahian TH, Ning YY, Yang Z, Pikkarainen T, Sankala M, Vargas SO, Takeya M, Tryggvason K, Kobzik L. MARCO is the major binding receptor for unopsonized particles and bacteria on human alveolar macrophages. J Immunol 2005; 175: 6058-64.

19. Ohtani K, Suzuki Y, Eda S, Kawai T, Kase T, Keshi H, Sakai Y, Fukuoh A, Sakamoto T, Itabe H, Suzutani T, Ogasawara M, Yoshida I, Wakamiya N. The membrane type collectin CL-P1 is a scavenger receptor on vascular endothelial cells. J Biol Chem 2001; 276: 44222-8.

20. Jang SJ, Ohtani K, Fukuoh A, Yoshizaki T, Fukuda M, Motomura W, Mori K, Fukuzawa J, Kitamoto N, Yoshida I, Suzuki Y, Wakamiya N. Scavenger receptor collectin placenta 1 (CL-P1) predominantly mediates zymosan phagocytosis by human vascular endothelial cells. J Biol Chem 2009; 284: 3956-65.

21. Auclair S, Milenkovic D, Besson C, Chauvet S, Gueux E, Morand C, Mazur A, Scalbert A. Catechin reduces atherosclerotic lesion development in apo E-deficient mice: a transcriptomic study. Atherosclerosis 2009; 204: 21-27.

22. Knowles DM 2nd, Tolidijian B, Marboe C, D’Agati VD, Grimes M, Chess L. Monoclonal anti-human monocyte antibodies OKM1 and OKM5 possess distinctive tissue distributions including differential reactivity with vascular endothelium. J. Immunol 1984; 132: 2170-3.

23. Tao N, Wagner SJ, Lublin DM. CD36 is palmitoylated on both N- and C-terminal cytoplasmic tails. J Biol Chem 1996; 271: 22315-20.

24. Febbraio M, Hajjar DP, Silverstein RL. CD36: a class B scavenger receptor involved in angiogenesis, atherosclerosis, inflammation, and lipid metabolism. J Clin Invest 2001; 108: 785-91.

25. Hoebe K, Georgel P, Rutschmann S, Du X, Mudd S, Crozat K, Sovath S, Shamel L, Hartung T, Zähringer U, Beutler B. CD36 is a sensor of diacylglycerides. Nature 2005; 433: 523-7.

26. Podrez EA, Febbraio M, Sheibani N, Schmitt D, Silverstein RL, Hajjar DP, Cohen PA, Frazier WA, Hoff HF, Hazen SL. Macrophage scavenger receptor CD36 is the major receptor for LDL modified by monocyte-generated reactive nitrogen species. J Clin Invest 2000; 105: 1095-108.

27. Febbraio M, Guy E, Silverstein RL. Stem cell transplantation reveals that absence of macrophage $\mathrm{CD} 36$ is protective against atherosclerosis. Arterioscler Thromb Vasc Biol 2004; 24: 2333-8. 
28. Guy E, Kuchibhotla S, Silverstein RL, Febbraio M. Continued inhibition of atherosclerotic lesion development in long term Western diet fed $\mathrm{CD} 36^{\circ} / \mathrm{apoE}^{\circ}$ mice. Atherosclerosis 2007; 192: 123-30.

29. Rahaman SO, Lennon DJ, Febbraio M, Podrez EA, Hazen SL, Silverstein RL. A CD36-dependent signalling cascade is necessary for macrophage foam cell formation. Cell Metab 2006; 4: 211-21.

30. Febbraio M, Podrez EA, Smith JD, Hajjar DP, Hazen SL, Hoff HF, Sharma K, Silverstein RL. Targeted disruption of the class B scavenger receptor $\mathrm{CD} 36$ protects against atherosclerotic lesion development in mice. J Clin Invest 2000; 105: 1049-56.

31. Silverstein RL. Type 2 scavenger receptor CD36 in platelet activation: the role of hyperlipemia and oxidative stress. Clin Lipidol 2009; 4: 767.

32. Podrez EA, Byzova TV, Febbraio M, Salomon RG, Ma Y, Valiyaveettil M, Poliakov E, Sun M, Finton PJ, Curtis BR, Chen J, Zhang R, Silverstein RL, Hazen SL. Platelet CD36 links hyperlipidemia, oxidant stress and a prothrombotic phenotype. Nat Med 2007; 13: 1086-95.

33. Göpfert MS, Siedler F, Siess W, Sellmayer A. Structural identification of oxidized acylphosphatidylcholines that induce platelet activation. J Vasc Res 2005; 42: 120-32.

34. Dawson DW, Pearce SF, Zhong R, Silverstein RL, Frazier WA, Bouck NP. CD36 mediates the in vitro inhibitory effects of thrombospondin-1 on endothelial cells. J Cell Biol 1997; 138: 707-17.

35. Li W, Febbraio M, Reddy SP, Yu DY, Yamamoto M, Silverstein RL. CD36 participates in a signaling pathway that regulates ROS formation in murine VSMCs. J Clin Invest 2010; 120: 3996-4006.

36. Silverstein RL, Li W, Park YM, Rahaman SO. Mechanisms of cell signaling by the scavenger receptor CD36: implications in atherosclerosis and thrombosis. Trans Am Clin Climatol Assoc 2010; 121: 206-20.

37. Medeiros LA, Khan T, El Khoury JB, Pham CL, Hatters DM, Howlett GJ, Lopez R, O’Brien KD, Moore KJ. Fibrillar amyloid protein present in atheroma activates CD36 signal transduction. $\mathrm{J}$ Biol Chem 2004; 279: 10643-8.

38. De Meyer GR, De Cleen DM, Cooper S, Knaapen MW, Jans DM, Martinet W, Herman AG, Bult H, Kockx MM. Platelet phagocytosis and processing of $\beta$-amyloid precursor protein as a mechanism of macrophage activation in atherosclerosis. Circ Res 2002; 90: 1197-204.

39. Silver DL. SR-BI and protein-protein interactions in hepatic high density lipoprotein metabolism. Rev Endocr Metab Disord 2004; 5: 327-33.

40. Krieger M. Charting the fate of the "good cholesterol": identification and characterization of high-density lipoprotein receptor SR-BI. Annu Rev Biochem 1999; 68: 523-58.

41. Kozarsky KF, Donahee MH, Rigotti A, Iqbal SN, Edelman E, Krieger M. Overexpression of the HDL receptor SR-BI alters plasma HDL and bile cholesterol levels. Nature 1997; 387: 414-7.

42. Ashraf MZ, Kar NS, Chen X, Choi J, Febbraio M, Podrez EA. Specific oxidized phospholipids inhibit scavenger receptors BI mediated selective uptake of cholesteryl esters. J Biol Chem 2008; 283: 10408-14.

43. Hirano K, Yamashita S, Nakagawa Y, Ohya T, Matsuura F, Tsukamoto K, Okamoto Y, Matsuyama A, Matsumoto K, Miyagawa J, Matsuzawa Y. Expression of human scavenger receptor class B type I in cultured human monocyte-derived macrophages and atherosclerotic lesions. Circ Res 1999; 85: 108-16.
44. Stangl H, Cao G, Wyne KL, Hobbs HH. Scavenger receptor, class B, type I-dependent stimulation of cholesterol esterification by high density lipoproteins, low density lipoproteins, and nonlipoprotein cholesterol. J Biol Chem 1998; 273: 31002-8.

45. Zhang W, Yancey PG, Su YR, Babaev VR, Zhang Y, Fazio S, Linton MF. Inactivation of macrophage scavenger receptor class B type I promotes atherosclerotic lesion development in apolipoprotein E deficient mice. Circulation 2003; 108: 2258-63.

46. Van Eck M, Bos IS, Hildebrand RB, Van Rij BT, Van Berkel TJ. Dual role for scavenger receptor class B, type I on bone marrowderived cells in atherosclerotic lesion development. Am J Pathol 2004; 165: 785-94.

47. Seetharam D, Mineo C, Gormley AK, Gibson LL, Vongpatanasin W, Chambliss KL, Hahner LD, Cummings ML, Kitchens RL, Marcel YL, Rader DJ, Shaul PW. High-density lipoprotein promotes endothelial cell migration and reendothelialization via scavenger receptor-B type I. Circ Res 2006; 98: 63-72.

48. Imachi H, Murao K, Cao W, Tada S, Taminato T, Wong NC, Takahara J, Ishida T. Expression of human scavenger receptor B1 on and in human platelets. Arterioscler Thromb Vasc Biol 2003; 23: 898-904.

49. Dole VS, Matuskova J, Vasile E, Yesilaltay A, Bergmeier W, Bernimoulin M, Wagner DD, Krieger M. Thrombocytopenia and platelet abnormalities in high-density lipoprotein receptor deficient mice. Arterioscler Thromb Vasc Biol 2008; 28: 1111-6.

50. Korporaal SJ, Meurs I, Hauer AD, Hildebrand RB, Hoekstra M, Ten Cate HT, Praticò D, Akkerman JW, Van Berkel TJ, Kuiper J, Van Eck M. Deletion of the high-density lipoprotein receptor scavenger receptor BI in mice modulates thrombosis susceptibility and indirectly affects platelet function by elevation of plasma free cholesterol. Arterioscler Thromb Vasc Biol 2011; 31: 34-42.

51. Ma Y, Ashraf MZ, Podrez EA. Scavenger receptor BI modulates platelet reactivity and thrombosis in dyslipidemia. Blood 2010; 116: 1932-41.

52. Valiyaveettil M, Kar N, Ashraf MZ, Byzova TV, Febbraio M, Podrez EA. Oxidized high-density lipoprotein inhibits platelet activation and aggregation via scavenger receptor BI. Blood 2008; 111: 1962-71.

53. Sun B, Boyanovsky BB, Connelly MA, Shridas P, van der Westhuyzen DR, Webb NR. Distinct mechanisms for OxLDL uptake and cellular trafficking by class B scavenger receptors CD36 and SR-BI. J Lipid Res 2007; 48: 2560-70.

54. Moestrup SK, Moller HJ. CD163: a regulated hemoglobin scavenger receptor with a role in the anti-inflammatory response. Ann Med 2004; 36: 347-54.

55. Gleissner CA, Shaked I, Erbel C, Böckler D, Katus HA, Ley K. CXCL4 downregulates the atheroprotective hemoglobin receptor CD163 in human macrophages. Circ Res 2010; 106: 203-11.

56. Ramprasad MP, Fischer W, Witztum JL, Sambrano GR, Quehenberger O, Steinberg D. The 94- to 97-kDa mouse macrophage membrane protein that recognizes oxidized low density lipoprotein and phosphatidylserine-rich liposomes is identical to macrosialin, the mouse homologue of human CD68. Proc Natl Acad Sci USA 1995; 92: 9580-4.

57. Ramprasad MP, Terpstra V, Kondratenko N, Quehenberger O, Steinberg D. Cell surface expression of mouse macrosialin and human CD68 and their role as macrophage receptors for oxidized low density lipoprotein. Proc Natl Acad Sci USA 1996; 93: 14833-8.

58. de Beer MC, Zhao Z, Webb NR, van der Westhuyzen DR, de Villiers WJ. Lack of a direct role for macrosialin in oxidized LDL metabolism. J Lipid Res 2003; 44: 674-85. 
59. Sawamura T, Kume N, Aoyama T, Moriwaki H, Hoshikawa H, Aiba Y, Tanaka T, Miwa S, Katsura Y, Kita T, Masaki T. An endothelial receptor for oxidized low-density lipoprotein. Nature 1997; 386: 73-7.

60. Kataoka H, Kume N, Miyamoto S, Minami M, Moriwaki H, Murase T, Sawamura T, Masaki T, Hashimoto N, Kita T. Expression of lectin-like oxidized low-density lipoprotein receptor-1 in human atherosclerotic lesions. Circulation 1999; 99: 3110-7.

61. Li D, Mehta JL. Antisense to LOX-1 inhibits oxidized LDLmediated upregulation of monocyte chemoattractant protein-1 and monocyte adhesion to human coronary artery endothelial cells. Circulation 2000; 101: 2889-95.

62. Nagase M, Hirose S, Sawamura T, Masaki T, Fujita T. Enhanced expression of endothelial oxidized low-density lipoprotein receptor (LOX-1) in hypertensive rats. Biochem Biophys Res Commun 1997; 237: 496-8.

63. Mehta JL, Chen J, Hermonat PL, Romeo F, Novelli G. Lectinlike, oxidized low-density lipoprotein receptor-1 (LOX-1): a critical player in the development of atherosclerosis and related disorders. Cardiovasc Res 2006; 69: 36-45.

64. Kakutani M, Masaki T, Sawamura T. A platelet-endothelium interaction mediated by lectin-like oxidized low-density lipoprotein receptor-1. Proc Natl Acad Sci USA 2000; 97: 360-4.

65. Chen M, Kakutani M, Naruko T, Ueda M, Narumiya S, Masaki T, Sawamura T. Activation-dependent surface expression of LOX-1 in human platelets. Biochem Biophys Res Commun 2001; 282: 153-8.

66. Takahashi Y, Fuda H, Yanai H, Akita H, Shuping H, Chiba H, Matsuno K. Significance of membrane glycoproteins in platelet interaction with oxidized low-density lipoprotein. Semin Thromb Hemost 1998; 24: 251-3.

67. Tamura Y, Osuga J, Adachi H, Tozawa R, Takanezawa Y, Ohashi K, Yahagi N, Sekiya M, Okazaki H, Tomita S, Iizuka Y, Koizumi H, Inaba T, Yagyu H, Kamada N, Suzuki H, Shimano H, Kadowaki T, Tsujimoto M, Arai H, Yamada N, Ishibashi S. Scavenger receptor expressed by endothelial cells I (SREC-I) mediates the uptake of acetylated low density lipoproteins by macrophages stimulated with lipopolysaccharide. J Biol Chem 2004; 279: 30938-44.

68. Greaves DR, Gordon S. Thematic review series: the immune system and atherogenesis. Recent insights into the biology of macrophage scavenger receptors. J Lipid Res 2005; 46: 11-20.

69. Shimaoka T, Nakayama T, Kume N, Takahashi S, Yamaguchi J, Minami M, Hayashida K, Kita T, Ohsumi J, Yoshie O, Yonehara S. Cutting edge: SR-PSOX/CXC chemokine ligand 16 mediates bacterial phagocytosis by APCs through its chemokine domain. J Immunol 2003; 171: 1647-51.

70. Minami M, Kume N, Shimaoka T, Kataoka H, Hayashida K, Akiyama Y, Nagata I, Ando K, Nobuyoshi M, Hanyuu M, Komeda M, Yonehara S, Kita T. Expression of SR-PSOX, a novel cell-surface scavenger receptor for phosphatidylserine and oxidized LDL in human atherosclerotic lesions. Arterioscler Thromb Vasc Biol 2001; 21: 1796-800.

71. Aslanian AM, Charo IF. Targeted disruption of the scavenger receptor and chemokine CXCL16 accelerates atherosclerosis. Circulation 2006; 114: 583-90.

72. Yamauchi R, Tanaka M, Kume N, Minami M, Kawamoto T, Togi K, Shimaoka T, Takahashi S, Yamaguchi J, Nishina T, Kitaichi M, Komeda M, Manabe T, Yonehara S, Kita T. Up-regulation of SR-PSOX/CXCL16 and recruitment of $\mathrm{CD}^{4+} \mathrm{T}$ cells in cardiac valves during inflammatory valvular heart disease. Arterioscler Thromb Vasc Biol 2004; 24: 282-7.

73. Siegel-Axel D, Daub K, Seizer P, Lindemann S, Gawaz M. Platelet lipoprotein interplay: trigger of foam cell formation and driver of atherosclerosis. Cardiovasc Res 2008; 78: 8-17.

74. Hildebrand RB, Lammers B, Meurs I, Korporaal SJ, De Haan W, Zhao Y, Kruijt JK, Praticò D, Schimmel AW, Holleboom AG, Hoekstra M, Kuivenhoven JA, Van Berkel TJ, Rensen PC, Van Eck M. Restoration of high-density lipoprotein levels by cholesteryl ester transfer protein expression in scavenger receptor class B type I (SR-BI) knockout mice does not normalize pathologies associated with SR-BI deficiency. Arterioscler Thromb Vasc Biol 2010; 30: 1439-45.

75. Stephen SL, Freestone K, Dunn S, Twigg MW, HomerVanniasinkam S, Walker JH, Wheatcroft SB, Ponnambalam S. Scavenger receptors and their potential as therapeutic targets in the treatment of cardiovascular disease. Int J Hypertens 2010; 2010: 646929.

76. Ockenhouse CF, Tandon NN, Magowan C, Jamieson GA, Chulay JD. Identification of a platelet membrane glycoprotein as a Falciparum malaria sequestration receptor. Science 1989; 243: 1469-71.

77. Ren Y, Silverstein RL, Allen J, Savill J. CD36 gene transfer confers capacity for phagocytosis of cells undergoing apoptosis. J Exp Med 1995; 181: 1857-62.

78. Greenberg ME, Sun M, Zhang R, Febbraio M, Silverstein R, Hazen SL. Oxidized phosphatidylserine-CD36 interactions play an essential role in macrophage-dependent phagocytosis of apoptotic cells. Cell Metab 2006; 4: 211-21.

79. Kennedy DJ, Kuchibhotla S, Westfall KM, Silverstein RL, Morton RE, Febbraio M. A CD36-dependent pathway enhances macrophage and adipose tissue inflammation and impairs insulin signalling. Cardiovasc Res 2011; 89: 604-13.

80. Braun A, Trigatti BL, Post MJ, Sato K, Simons M, Edelberg JM, Rosenberg RD, Schrenzel M, Krieger M. Loss of SR-BI expression leads to the early onset of occlusive atherosclerotic coronary artery disease, spontaneous myocardial infarctions, severe cardiac dysfunction, and premature death in apolipoprotein E-deficient mice. Circ Res 2002; 90: 270-6.

Received February 7, 2012; accepted April 2, 2012 


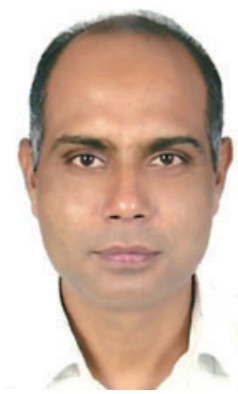

Dr. M. Zahid Ashraf is currently leading the Genomics Group at Defense Institute of Physiology and Allied Sciences (DIPAS), Delhi, India. He has received his Post Doctoral Training from Lerner Research Institute, Cleveland Clinic, Cleveland, USA. During his tenure at Cleveland he has worked in the area of Cardiovascular Biology, especially the involvement of Scavenger Receptors in Atherothrombotic Disorders. $\mathrm{He}$ has made a significant contribution in the area of atherosclerosis by exploring the role of lipoproteins and oxidized phospholipids in foam cell formation. Dr. Ashraf, to his credit, has published around 20 papers in International Journals including Blood, Circulation Research, MCB, JBC etc. He has been a recipient of prestigious Cleveland Clinic Innovation Award in 2008.

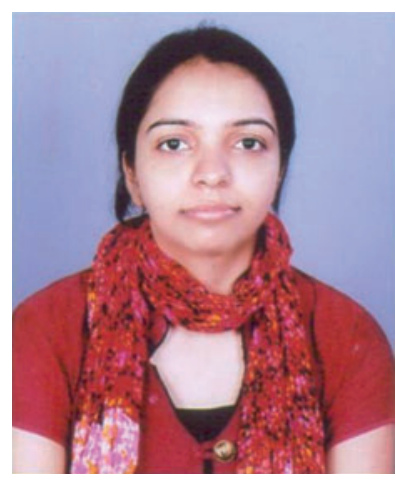

Anita Sahu is a talented graduate student under the mentorship of Mohammad Z Ashraf at Defense Institute of Physiology and Allied Sciences (DIPAS), Delhi, India. Her ongoing research deals with understanding the pathophysiology of thrombotic disorders. She is actively involved in a wide spectrum of research ranging from gene expression analysis, epigenetic modifications of nucleic acid to gene regulation by microRNA studies. 